\title{
Lyophilized yeast powder for adjuvant free thermostable vaccine delivery
}

\author{
Ravinder Kumar ${ }^{1}$ (D) Bhushan N. Kharbikar ${ }^{2}$ (D) \\ Received: 9 December 2020 / Revised: 16 March 2021 / Accepted: 30 March 2021 / Published online: 9 April 2021 \\ (C) This is a U.S. government work and not under copyright protection in the U.S.; foreign copyright protection may apply 2021
}

\begin{abstract}
Thermolabile nature of commercially available vaccines necessitates their storage, transportation, and dissemination under refrigerated condition. Maintenance of continuous cold chain at every step increases the final cost of vaccines. Any breach in the cold chain even for a short duration results in the need to discard the vaccines. As a result, there is a pressing need for the development of thermostable vaccines. In this proof-of-concept study, we showed that $E$. coli curli-green fluorescent fusion protein remains stable in freeze-dried yeast powder for more than 18 and 12 months when stored at $30{ }^{\circ} \mathrm{C}$ and $37{ }^{\circ} \mathrm{C}$ respectively. Stability of the heterologous protein remains unaffected during the process of heat-inactivation and lyophilization. The mass of lyophilized yeast powder remains almost unchanged during the entire period of storage and expressed protein remains intact even after two cycles of freeze and thaws. The protease-deficient strain appears ideal for the development of whole recombinant yeast-based vaccines. The cellular abundance of expressed antigen in dry powder after a year was comparable to freshly lyophilized cells. Scanning electron microscopy showed the intact nature of cells in powdered form even after a year of storage at $30{ }^{\circ} \mathrm{C}$. Observation made in this study showed that freeze-dry yeast powder can play a vital role in the development of thermostable vaccines.
\end{abstract}

\section{Key Points}

- Yeast-based vaccines can overcome problem of cold chain associated with conventional vaccines

- Lyophilized yeast powder can be a simple way for long-term storage of immunogen(s)

- Protease deficient strain is important for whole recombinant yeast-based vaccines

Keywords Yeast-based vaccine, $\cdot$ P. pastoris, $\cdot$ Long-term-stability, $\cdot$ Lyophilized, $\cdot$ Yeast powder, $\cdot$ Thermostable

\section{Introduction}

In the last century, vaccines have proved to be one of the most important medical interventions in the fight against infectious diseases. Eradication of smallpox in 1980 (Fenner 1982) and soon polio (Norrby et al. 2017) are important success stories associated with the benefits of vaccines in public health. Widespread application of vaccines also leads to a sharp decline in newer cases of tuberculosis, hepatitis, measles,

Ravinder Kumar raj86tau@gmail.com

1 Department of Obstetrics, Gynecology and Reproductive Sciences, University of California San Francisco, San Francisco, CA 94143, USA

2 Department of Bioengineering and Therapeutic Sciences, University of California San Francisco, San Francisco, CA 94158, USA tetanus and other infectious diseases (Versteeg et al. 2019). The importance of vaccines can also be underscored by the fact that there is a race for vaccine development against severe acute respiratory syndrome coronavirus-2 responsible for present coronavirus disease of 2019 pandemic (Callaway 2020). As per World Health Organization estimates every year around 2-3 million lives are saved by vaccine application (Cruz-Reséndiz et al. 2020). Still millions of individuals (out of which majority are children below 5 years of age) die from vaccine-preventable diseases. Despite the significant efforts at every step millions of people are left unvaccinated thus putting them at the risk of getting the infection at some point in life. According to the Global Vaccine Action Plan 2011-2020 review report, approximately 19.4 million infants did not receive lifesaving vaccines in 2018 (https://www.who.int/ immunization/globalvaccine_action_plan/en/).

Among the various issues associated with presently licensed vaccines (Kumar and Kumar 2019), inherent 
thermolabile nature of these vaccines makes their storage, transportation and dissemination a daunting task. In the field of vaccines, this is commonly known as the "Cold Chain" problem and at every step maintenance of refrigerated condition $\left(2-8{ }^{\circ} \mathrm{C}\right.$ in general) is a must. In many instances, maintenance of continuous cold chain raises the cost of the vaccines by about $80 \%$ (Bandau et al. 2003; Das 2004). Exposure of vaccine to sub-optimal temperature even for short duration leads to vaccine degradation and dramatic loss in efficacy which forces almost $50 \%$ of the vaccines to be discarded before their application (Brandau et al. 2003; Hill et al. 2016). This scenario becomes even more relevant in resource-poor settings in countries of Asia and Africa which lack access to vaccines (Chen and Kristensen 2009; Das 2004). Therefore, improving the thermal stability of available vaccines at ambient temperature is highly desirable.

To address the problem of poor thermal stability and short shelf life of vaccines at ambient temperature, different approaches have been taken in the past. Example in the case of human enterovirus type 71 , biomineralization of virus particle improves thermal stability significantly (Wang et al. 2013). Modification in a liquid formulation was also found encouraging. For example, the addition of stabilizers like deuterium oxide, proteins, $\mathrm{MgCl}_{2}$ and non-reducing sugars in vaccine formulation improves their thermal stability (Milistien et al. 1997; Alcock et al. 2010). Similarly, the addition of anionic nanogold particles and polyethene glycol improve the thermal stability of some of the vaccines significantly (Pelliccia et al. 2016). Recently, the coating of bacterial cells or viral particles in a thin film of sugar gave promising results (Leung et al. 2019; Bajrovic et al. 2020). All the above-highlighted approaches used the addition of one or more chemicals in vaccine preparation which necessitates additional safety tests and other regulatory procedures. Moreover, the application of all the aforementioned approaches kept the vaccine stable only for a short duration depending upon vaccine and storage temperature. Use of these approaches makes the entire process lengthier and more cumbersome. Therefore, a procedure which is simple, cost-effective, safe, while improving the thermal stability and shelf life of a vaccine at ambient temperature will be desirable.

Lyophilization has been shown to improve the stability of whole cells (example bacterial cell) and viral particles that are regularly used in conventional vaccines preparation (Wang et al. 2012; Maa et al. 2004; Garmise et al. 2007). This forced us to investigate whether whole recombinant yeast lyophilized powder can keep the heterologous protein (acting as an immunogen) intact when stored at ambient temperature. In this proof-of-concept study, we showed that protein antigen remains stable in lyophilized yeast powder for 1.5 years and 1 year when stored at $30^{\circ} \mathrm{C}$ and $37^{\circ} \mathrm{C}$ respectively. The observations from this study will help in developing a thermostable vaccine with long shelf life even under non-refrigerator condition $\left(2-8{ }^{\circ} \mathrm{C}\right)$ using a yeast-based platform.

\section{Materials and methods}

\section{Yeast strains}

Haploid auxotrophic PPY12h (arg4 his4) (Gould et al. 1992) and protease-deficient SMD1163 (pep4prb1 his4) (Gleeson et al. 1998) strains of Komagataella phaffii or K. phaffii (formerly known as Pichia pastoris or P. pastoris) were used in the entire study (Kurtzman 2009; Kumar et al. 2020).

\section{Media}

YPAD media ( $1 \%$ yeast extract, $2 \%$ peptone, $0.05 \%$ adenine, and $2 \%$ dextrose), SD+CSM-His plate $(0.17 \%$ YNB without amino acid and ammonium sulfate, $0.5 \%$ ammonium sulfate, 0.08\% CSM-His, 2\% agar, 2\% dextrose) (Kumar 2019).

\section{Culture condition and protein expression}

All yeast culturewas carried out at $30{ }^{\circ} \mathrm{C}, 230 \mathrm{rpm}$. Since expression of recombinant fusion protein was under constitutive glyceraldehydes-3 phosphate dehydrogenase promoter, conditions for protein expression were same as that of culture growth.

\section{Cloning of $E$. coli curli protein}

Synthetic construct coding for $E$. coli curli (CSGA) was synthesized by a commercial vendor (Genewiz, New Jersey, USA) into a pUC57-Amp vector. Fragment coding for curli open reading frame was excised from the vector and subcloned into $K$. phaffii integrating vector pIB2 (Sears et al. 1998) into which cycle -3 GFP (green fluorescent protein) was cloned previously (Crameri et al. 1996). The sequence of ORF was the same as that of the original construct for which sequence was deposited in Genebank with the following accession number MH264502 (Kumar 2018). The combined mass of the fusion protein was $42.9 \mathrm{kDa}$. It is important to note that codon optimization was not performed for the construct used in this study.

\section{Yeast transformation}

K. phaffii transformation was performed as described previously (Kumar 2019) and briefly mentioned here. The final plasmid (pRK10) was linearized by digestion with EcoNI which cleaves within the HIS4 marker gene. Linearized plasmid was transformed into PPY12h and SMD1 163 strain using the electroporation method (GenePulser Xcell from Biorad). Transformants were selected on $\mathrm{His}^{-}$plates and positive transformants were confirmed both by the fluorescent microscopy and western blot. 


\section{Protein extraction from regular cycling cells}

Presence of E. coli CSGA-GFP protein in K. phaffii was confirmed by detecting CSGA-GFP fusion protein using polyclonal rabbit anti-GFP antibodies (from Life Technologies USA; cat \# A-11122). Amount of protein was normalized based on either the number of cells or by dry mass of cells. Cells were treated with $12.5 \%$ TCA (Trichloro acetic acid) and samples were incubated at $-80^{\circ} \mathrm{C}$ for one $\mathrm{h}$ or overnight. On completion of incubation, samples were thawed at room temperature and the samples were centrifuged at $12000 \mathrm{~g}$ for 8 min. The supernatant was discarded and the pellet was washed twice with $80 \%$ chilled acetone. Finally, protein pellet was airdried and was resuspended in $150 \mu \mathrm{L} 1 \%$ SDS and $0.2 \mathrm{~N}$ $\mathrm{NaOH}$. Then $150 \mu \mathrm{L} 2 \times$ dye $(100 \mathrm{mM}$ Tris $\mathrm{HCl} \mathrm{pH} 6.8$, $200 \mathrm{mM}$ DTT, $4 \%$ SDS, $0.2 \%$ bromophenol blue, $20 \%$ glycerol) was added to the sample and samples were heated for 5 min at $95{ }^{\circ} \mathrm{C}$ using dry heating block. Samples were cooled down to room temperature, vortexed, spanned and an equal amount or volume of samples was loaded in each well of $10 \%$ sodium dodecyl sulphate-polyacrylamide gel electrophoresis (SDS-PAGE) along with pre-stained protein marker (Biorad, cat \# 161-0376). Samples were run at constant 100V till the dye front reaches the bottom of the gel (Kumar 2019).

\section{Western blot}

On completion of SDS-PAGE run, proteins were transferred onto nitrocellulose membrane by wet transfer (at constant $100 \mathrm{~V}$ for $1 \mathrm{~h}$ at $4{ }^{\circ} \mathrm{C}$ ) as described elsewhere (Towbin et al. 1979; Kumar et al. 2014). The blotting membrane was incubated in blocking buffer (5\% nonfat skimmed milk powder in TBST) (TBST, $137 \mathrm{mM} \mathrm{NaCl}, 2.7 \mathrm{mM} \mathrm{KCl}, 19 \mathrm{mM}$ Tris base, $0.1 \%$ Tween 20 ) for $1 \mathrm{~h}$ and then incubated with antiGFP antibodies overnight at $4{ }^{\circ} \mathrm{C}$ under gentle shaking condition. Primary antibodies were removed, and the membrane was washed thrice with TBST. The membrane was again incubated with IRDye ${ }^{\circledR} 800 \mathrm{CW}$ goat anti-rabbit secondary antibodies (from LI-COR, USA; cat \# 926-32211) for one h at room temperature. The membrane was again washed thrice with TBST and blot was scanned on Odyssey Infrared Imager using LI-COR Odyssey software 2.1 (from LI-COR, Nebraska, USA) as per manufacturer instructions.

\section{Heat inactivation of recombinant $K$. phaffii}

A single colony of recombinant $K$. phaffii expressing $E$. coli CSGA-GFP under GAP promoter was inoculated into $5 \mathrm{~mL}$ of YPAD tube. The tube was incubated at $30^{\circ} \mathrm{C}, 230 \mathrm{rpm}$ for overnight growth (source of inoculum). The overnight grew culture was used for the inoculation of $500 \mathrm{~mL}$ YPAD in $2.8 \mathrm{~L}$ flasks. The flasks were incubated at $30^{\circ} \mathrm{C}, 230 \mathrm{rpm}$ for $48 \mathrm{~h}$. Cells were pelleted by centrifugation at $3000 \mathrm{~g}$ for $5 \mathrm{~min}$. Cells were washed twice with sterile water. Finally, the cell pellet was resuspended in $25 \mathrm{~mL}$ sterile water and tube was incubated in a water bath maintained at $56^{\circ} \mathrm{C}$ for 90 min for heatinactivation of yeast cells (Haller et al. 2007). After 90 min, tubes were taken out of a water bath, cooled to room temperature. A small volume $(10 \mu \mathrm{L})$ of cell suspension was taken out and plated on YPAD plate to check for the presence of viable cells. The remaining cell suspension was centrifuged at $3000 \mathrm{~g}$ for $5 \mathrm{~min}$, the supernatant was discarded and pellet in tubes was put for lyophilization as described below.

\section{Lyophilization (freeze-drying) of whole recombinant K. phaffii}

Recombinant $K$. phaffii was lyophilized as described elsewhere (Patterson et al. 2015) and briefly mentioned here. Cells were harvested in $50 \mathrm{~mL}$ falcon tube by centrifugation at $3000 \mathrm{~g}$ for $5 \mathrm{~min}$ and supernatant was discarded. Lyophilization was performed on the cell pellet using the AdVantage 2.0 Bench Top Freeze Dryer/Lyophilizer (from SP Scientific). Samples in tubes were regularly checked for the formation of lyophilized powder. On completion of lyophilization tubes were taken off and the combined mass of tube and lyophilized yeast powder was noted.

\section{Storage of freeze-dried yeast powder}

On completion of the process of freeze-drying, tubes were removed from the lyophilizer and caps were tightly closed. Tubes were kept in cardboard boxes and stored in a separate incubator (in the dark away from direct sunlight) operating at $30{ }^{\circ} \mathrm{C}$ and $37^{\circ} \mathrm{C}$. Then the weight of tubes was noted at a regular interval.

\section{Protein extraction from lyophilized powder}

A known amount of lyophilized yeast powder was taken in a sterile Eppendorf tube. The powder was resuspended in 200 $\mathrm{uL}$ of $12.5 \% \mathrm{TCA}$ and stored at $-80^{\circ} \mathrm{C}$ for $1 \mathrm{~h}$ or overnight. The subsequent procedure is the same as described above for protein extraction.

\section{Freeze and thawing of lyophilized yeast powder}

As above, a known amount of lyophilized yeast powder was taken into fresh sterile Eppendorf tubes. Tubes were stored at $-20^{\circ} \mathrm{C}$ and $-80^{\circ} \mathrm{C}$ for $2 \mathrm{~h}$ followed by incubating the tubes at $30{ }^{\circ} \mathrm{C}$ for $2 \mathrm{~h}$. This process was repeated depending on the number of freeze-thaw cycles. A known amount of yeast powder was also taken and incubated at $30^{\circ} \mathrm{C}$ as a control. Protein extraction was performed as described above. 
Field emission scanning electron microscopy (FE-SEM)

The shape and surface morphology of lyophilized yeast cells stored at $30{ }^{\circ} \mathrm{C}$ for a year was analyzed by field emission scanning electron microscopy (ZEISS Gemini Sigma 500 VP, Carl Zeiss Microscopy LLC, NY, USA). Samples were prepared by mounting a small amount of lyophilized yeast powder on a double-sided carbon tape on a metal SEM stub. Gently, spread the yeast powder across the surface of the tape. Compressed air was used to remove loose lyophilized yeast cells. Yeast samples were sputter-coated with a 3-nm thin layer of Gold-Palladium for ensuring the conductivity for electrons beam. A beam strength of $5.0 \mathrm{kV}$ and a working distance in the range of 8-9 $\mathrm{mm}$ was used to visualize yeast samples.

\section{Fluorescence microscopy}

Expression of E. coli CSGA-GFP fusion protein in both SMD116 and PPY12h strain of $K$. phaffii was confirmed by fluorescence microscopy. For each strain, $100 \mathrm{uL}$ cycling cells were taken into sterile Eppendorf tube. Cells were pellet down by centrifugation at $3000 \mathrm{~g}$ for $3 \mathrm{~min}$. The supernatant was discarded, and the cell pellet was resuspended in $1 \mathrm{~mL}$ sterile Milli Q water. $5 \mathrm{uL}$ of cell suspension was transferred onto a glass slide. Cells were fixed by adding an equivalent volume of $1 \%$ agarose. Images were captured using plan apochromat $100 \times 1.40$-NA oil immersion objective on a motorized fluorescence microscope (Axioskop 2 MOT plus; Carl Zeiss) coupled to a monochrome digital camera (AxioCam MRm; Carl Zeiss). Image analysis was performed using Axio vision software (Kumar 2019).

\section{Quantitative western blot}

Quantitative western blot was performed as follows. 1, $2,3,4,5,6,7,8$, and $10 \mathrm{ng}$ of purified GFP was loaded into each well of $12 \%$ SDS-PAGE gel along with required protein samples. The rest of the procedure for western blot is the same as mentioned above. Blot was scanned at different exposure to get the best dynamic linear range for analysis of different brands. Band intensity calculation was performed by Image $\mathrm{J}$ analysis tools. A linear curve was prepared using a band intensity signal from purified GFP. This linear curve was used for calculating signal intensity form protein samples and expressed protein per mg of dry yeast powder was calculated. Before performing an actual experiment protein samples were diluted such that signal intensity from protein samples fall within a linear curve prepared using purified GFP.
Correlation between cell density and cell dry weight

Cells were grown as mentioned above and cell density was checked. Then 1, 2, 3, 4, 5, $6 \mathrm{OD}_{600 \mathrm{~nm}}$ of cells were transferred into sterile Eppendorf tubes and heat-inactivated as above. Cells were pelleted down and supernatant was discarded. Tubes with cell pellets were put for lyophilization as above. On completion of lyophilization tubes were taken off and mass of tubes along with yeast powder was measured. Mass of tubes after lyophilization was subtracted from mass of empty tubes to get the mass of yeast powder and plot was prepared between cell density and dry mass of cell.

\section{Results}

\section{Expression of E. coli CSGA-GFP in K. phaffii}

Curli is a bacterial surface protein (fimbri) involved in cell adhesion and biofilm formation (Barnhart and Chapman 2006; Nguyen et al. 2014). Curli is capable of raising immune response, thereby acting as a good immunogen (Barnhart and Chapman 2006) and a suitable candidate for the proof-ofconcept study. Cartoon presentation of the final plasmid used for the expression of E. coli CSGA-GFP fusion protein is shown in Fig. 1A. For checking the expression of the CSGA-GFP fusion protein, randomly eight colonies were selected and patched on a fresh selection plate (SD+CSM-His plate). Next day, the expression of the fusion protein was first confirmed by fluorescent microscopy (Fig. 1B for PPY12h background). Later in a separate experiment the same plasmid was transformed into SMD1163 strain. Integration of plasmid and expression of CSGA-GFP was confirmed by fluorescent microscopy (Fig. 1C). Expressed recombinant fusion protein localized in cytoplasm and vacuoles.

Expression of the fusion protein CSGA-GFP was again confirmed by western blot. $2 \mathrm{OD}_{600 \mathrm{~nm}}$ of cells were used for protein extraction for western blot. Blot image in Fig. 1D shows that all the selected colonies were positive. Ponceau S-stain image of the same blot is shown as a loading control (Fig. 1E) which confirm the proper loading of protein in each well. Specific anticipated bands are highlighted by an arrow pointing towards them. We do not get any band in empty vector strain used as a negative control. The absence of any signal from negative control shows the specificity of GFP antibodies used in the experiment. The expression of the heterologous protein was endogenous. Note, from $500 \mathrm{~mL}$ of culture, we were able to get around 10,000 $\mathrm{OD}_{600 \mathrm{~nm}}$ of cells which corresponds to (approx.) $1.05 \mathrm{~g}$ of dry cell powder (dry weight after lyophilization). 
Fig. 1 Expression of E. coli CSGA-GFP fusion protein in K. phaffii. (A) Map of the final CSGA-GFP fusion protein.

Expression of a CSGA-GFP fusion protein in (B) PPY12h and (C) SMD1163 strain. Scale bar represents $5 \mathrm{uM}$. (D) Image of western blot showing expression in PPY12h. Bands of interest are while free GFP is pointed by an Asterisk mark. (E) Proper loading and protein transfer are shown by Ponceau S-stained blot image.

Well, 1 (pre-stained protein marker), well 2 (empty vector as a negative), well 3-8 (transformants) plasmid used for expression of the of the CSGA-GFP fusion protein pointed by arrows towards them

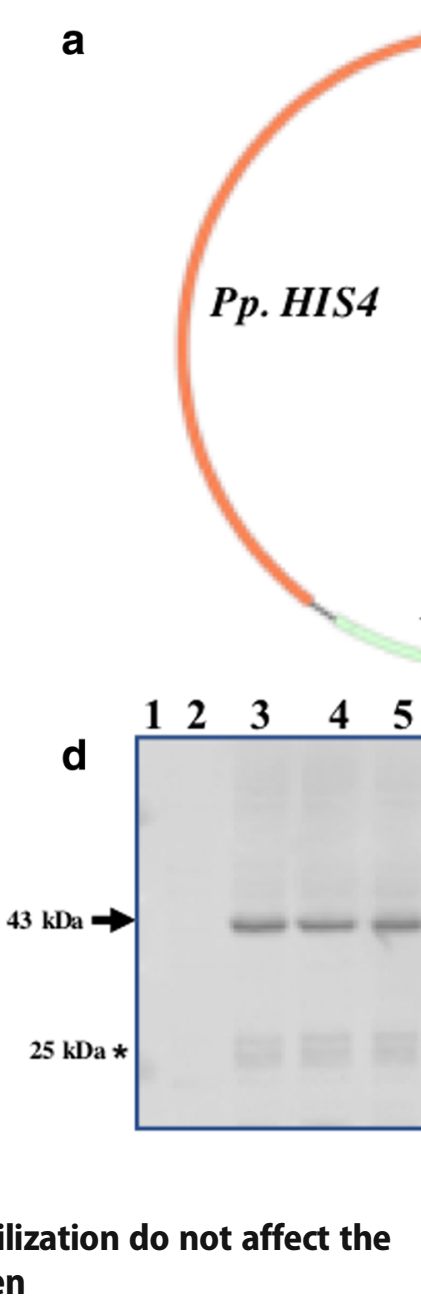

\section{Heat inactivation and lyophilization do not affect the stability of expressed antigen}

Yeast species especially S. cerevisiae and $K$. phaffii are nonpathogenic and are in the list of Generally Recognized As Safe, and routinely used for the production of diverse biomolecules for human consumption (Ramchuran et al. 2005; Basanta et al. 2010). Even then direct administration of live recombinant yeast cells into human subjects is not advisable from point of safety and moral ethics. Furthermore, the level of immune response mounted on the application of whole recombinant yeast is independent of live or dead nature of yeast ( $\mathrm{Lu}$ et al. 2004; Franzusoff et al. 2005) suggesting that inactivated recombinant yeast can be used without compromising on level of immune response. Heat-inactivation of yeast is rapid, simple, and more convenient compared to chemical based-inactivation of bacterial or viral particles for vaccine preparation. The combined effect of heat-inactivation and lyophilization on the stability of heterologous protein was missing and through this study we tried to fill that gap.

Heat inactivation was confirmed by plating small volume of cell suspension on YPAD plates (Fig. 2B) along with untreated control cycling cells (Fig. 1A). Our present western blot data showed that the stability of heterologous proteins remains essentially unaffected during heat-inactivation (Fig.
2C) and heat-inactivation followed by lyophilization (Fig. 2E). Proper loading and transfer of protein are shown by Ponceau S-stained blots (Fig. 2D and F respectively). Protein amount was normalized by the weight of cells used for protein extraction. Results of Fig. 2C are in accordance with our previous study (Kumar 2018). Based on the present data, it can be said that together heat-inactivation and lyophilization have no affect on protein stability.

\section{The protease-deficient yeast strain improves the stability of the expressed fusion protein}

In the previous section, we showed that process of heatinactivation and heat-inactivation followed by lyophilization does not affect the stability of CSGA-GFP in yeast cells. But we do see a very prominent band around $25 \mathrm{kDa}$ region of the blot. Whether the observed bands were due to degradation of the fusion protein on heat-inactivation followed by lyophilization or whether they were a result of cellular proteases activities was not clear. To sort out this, we transform the same construct into protease deficient strain (SMD1163) which lacks Prb1 (cytosolic) and Pep4 (vacuolar) protease. Our present western blot data pointed towards the fact that observed lower bands are the result of vacuolar protease action (Fig. 


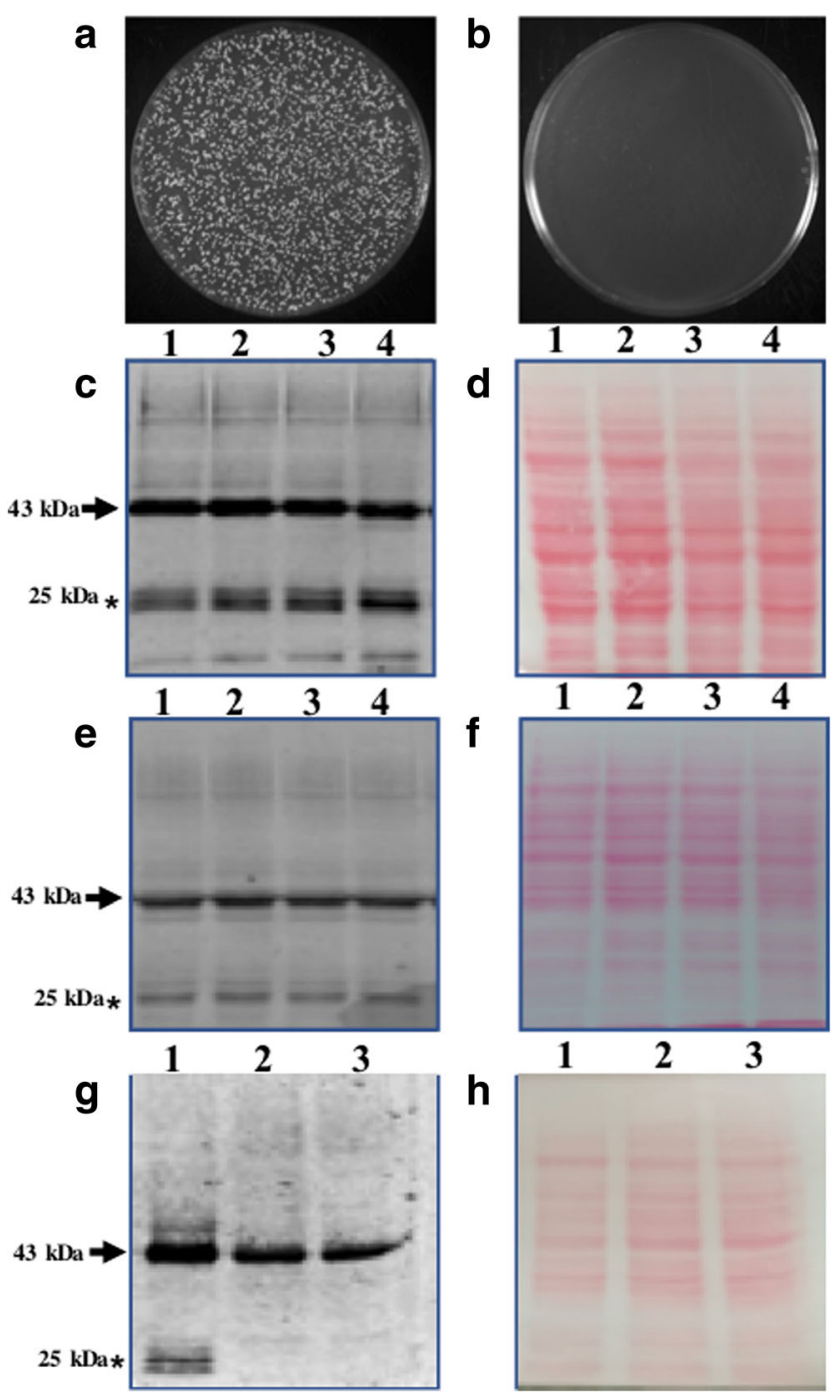

Fig. 2 Heat-inactivation and freeze-drying do not affect protein stability. (A) Control untreated viable cells. (B) Complete loss of viability on heatinactivation. (C) Western blot image showing the effect of heatinactivation on protein stability. Well, 1, 2 (untreated cycling cells); well 34 (heat-inactivated cells). (D) Proper loading and protein transfer is shown by Ponceau S-stain blot image. Western blot image showing the effect of freeze-drying on protein stability (E) well 1,2 (control cycling cells); well 3,4 (lyophilized yeast cells). (F) Proper loading and protein transfer is shown by Ponceau S-stain blot image. Bottom free GFP bands are due to vacuolar protease (G) well 1 (PPY12 strain); well 2-3 (SMD1163, protease deficient strain, lack Prb1, cytosolic and Pep4, vacuolar protease). (H) Proper loading and protein transfer is shown by Ponceau S-stain blot image. Bands of interest are pointed by arrows towards them, while free GFP is pointed by an asterisk mark

$2 \mathrm{G})$. Like previous blots, we again observed lower bands in PPY12h strain used as a control (Fig. 2G, well1) but failed to detect the same bands in SMD1163 (Fig. 2G, well 2,3). The presence or absence of lower bands in PPY12h and SMD1163 respectively is not due to the difference in the amount of protein loaded into each well was confirmed by Ponceau Sstained blot image (Fig. 2H). Therefore, it can be said that lower observed bands are not due to heat-inactivation or lyophilization but are the result of cellular protease activity. This observation is supported by the fact that during stress, autophagic pathways get activated which forces the degradation of cellular components in vacuoles or lysosomes (Klionsky et al. 2007; Takeshige et al. 1992; Kumar et al. 2020). Therefore, presence of lower bands in PPY $12 \mathrm{~h}$ and their absence in SMD1163 may be due to autophagic degradation of fusion proteins in vacuoles and release of free GFP $(26.7 \mathrm{kD}$ ) which is quite stable in vacuoles (whose free release in the vacuole is used in autophagic assays) was detected by antibodies (Klionsky et al. 2007; Takeshige et al. 1992).

\section{Mass of freeze-dried yeast powder remains un- changed during storage}

After confirming that heat-inactivation as well as freezedrying does not affect the stability of expressed protein, we increase the volume of culture to $1 \mathrm{~L}$. Cells were harvested, heat-inactivated, and freeze-dried. After lyophilization, tubes were taken off from lyophilizer, screwed the cap and weighed. Initial mass was taken and stored at $30{ }^{\circ} \mathrm{C}$ for 1 year. The weight of the tube was then checked regularly and sometimes the tubes were opened for a short time. Table 1 is showing the data for the mass of powder stored at $30{ }^{\circ} \mathrm{C}$. Similarly, we checked the weight of freeze-dried yeast powder stored at 37 ${ }^{\circ} \mathrm{C}$ for 6 months (Table 2). Present data showed that mass of freeze-dried powder remains essentially unchanged under both conditions of storage. The slight variation observed in weight may be due to moisture that might entered into tubes when tubes were open for some time. Note in Table 1 data is shown for two conditions. In one condition cells were lyophilized after-heat inactivation (Table 1 second and third column) and in other cells were lyophilized without heatinactivation (Table 1 fourth and fifth column). Based on the data shown in tables, it can be said that the mass of stored lyophilized cells does not change significantly.

Table 1 Mass of lyophilized yeast powder stored at $30^{\circ} \mathrm{C}$ for 1 year

\begin{tabular}{llllll}
\hline \multirow{2}{*}{ Month } & \multicolumn{2}{l}{ Heat-inactivated } & & \multicolumn{2}{l}{ Without heat-inactivated } \\
\cline { 2 - 3 } \cline { 5 - 6 } & Tube 1 & Tube 2 & & Tube 1 & Tube 2 \\
\hline $\mathbf{0}$ & 16.88 & 16.97 & & 17.06 & 17.26 \\
$\mathbf{2}$ & 16.97 & 16.96 & & 17.14 & 17.29 \\
$\mathbf{4}$ & 16.95 & 16.91 & & 17.14 & 17.27 \\
$\mathbf{6}$ & 16.98 & 16.93 & & 17.13 & 17.26 \\
$\mathbf{8}$ & 16.95 & 16.91 & & 17.15 & 17.21 \\
$\mathbf{1 0}$ & 16.96 & 16.93 & & 17.16 & 17.21 \\
$\mathbf{1 2}$ & 16.97 & 16.95 & & 17.15 & 17.22 \\
\hline
\end{tabular}

Net mass is in grams. Reported mass is the combined mass of tube and powder 
Table 2 Mass of heatinactivated lyophilized yeast powder stored at 37 ${ }^{\circ} \mathrm{C}$ for 6 months

\begin{tabular}{lll}
\hline Month & Tube 1 & Tube 2 \\
\hline $\mathbf{0}$ & 1.02 & 0.98 \\
$\mathbf{1}$ & 1.02 & 1.01 \\
$\mathbf{2}$ & 1.05 & 1.01 \\
$\mathbf{3}$ & 1.05 & 1.00 \\
$\mathbf{4}$ & 1.04 & 1.00 \\
$\mathbf{5}$ & 1.05 & 1.00 \\
$\mathbf{6}$ & 1.05 & 1.00 \\
\hline
\end{tabular}

Net mass is in grams (reported are the values after deducting mass of empty tube)

\section{Cells in lyophilized powder retain their intactness}

Next, we asked whether cells in lyophilized powder remain intact or not. This was done by checking the morphology and surface appearance of cells using SEM microscopy. A small amount of lyophilized powder (Fig. 3A cells were lyophilized without heat-inactivation and, Fig. 3B cells were lyophilized after heat-inactivation) was taken and SEM microscopy was performed. SEM images showed that the cells remain intact in lyophilized powdered form when stored at $30{ }^{\circ} \mathrm{C}$ for more than a year (Fig. 3C and D). Although cells were intact under both the condition, we observed a difference in the texture of the powder. Freeze dry powder of cells without heatinactivation appears less compact and less dense (Fig. 3A) whereas heat-inactivated powder appears more compact and denser (Fig. 3B). Thus, it can be said that cells in lyophilized powdered form remain intact for a year even when stored under ambient or room temperature.

\section{Expressed antigen remains stable in lyophilized yeast powder stored at $30^{\circ} \mathrm{C}$ temperature}

Although SEM data in the previous section confirmed intact nature of lyophilized yeast cells after 1 year of storage at 30 ${ }^{\circ} \mathrm{C}$, whether expressed protein also remained intact was unknown. To check the stability of the expressed protein, we took equal amounts of lyophilized powder from both the conditions and the proteins were extracted. Equal amount of whole cell lysate was loaded on 10\% SDS-PAGE and the fusion protein was detected using anti-GFP antibodies. Present western blot data showed that expressed protein remains stable in powdered yeast stored at $30^{\circ} \mathrm{C}$ for a 1.5 years (Fig. 4). The expressed protein remains stable under both the conditions in which cells were lyophilized without heat-
Fig. 3 Cells in lyophilized powder remain intact for more than a year. Image of lyophilized yeast powder stored at $30^{\circ} \mathrm{C}$ for more than a year (A) cells was lyophilized without heatinactivation and (B) cells were heat-inactivated before lyophilization. SEM images showing external morphology of lyophilized cells after 1 year (C) lyophilized cells without heat-inactivation and (D) lyophilized cells after heat-inactivation
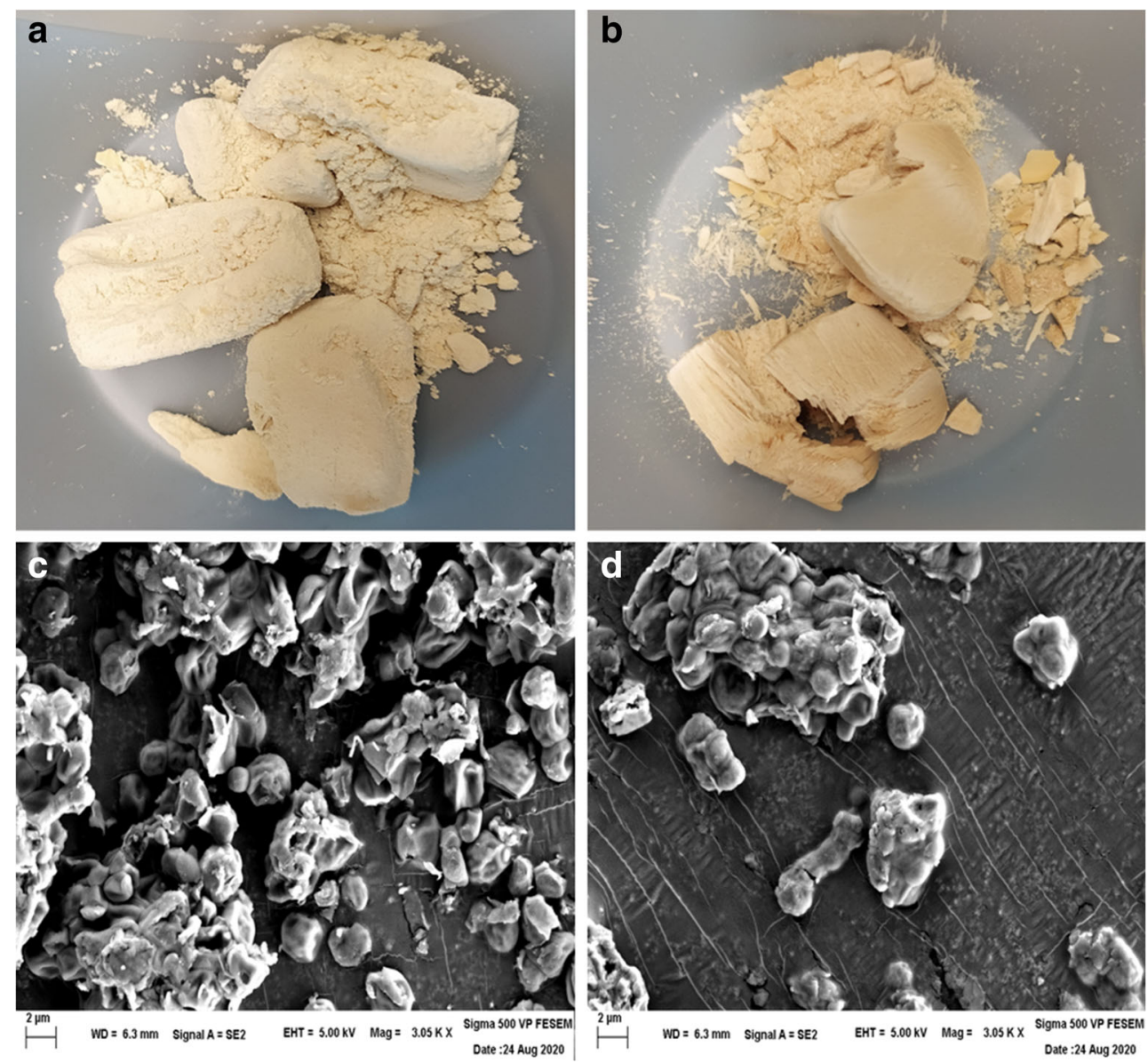


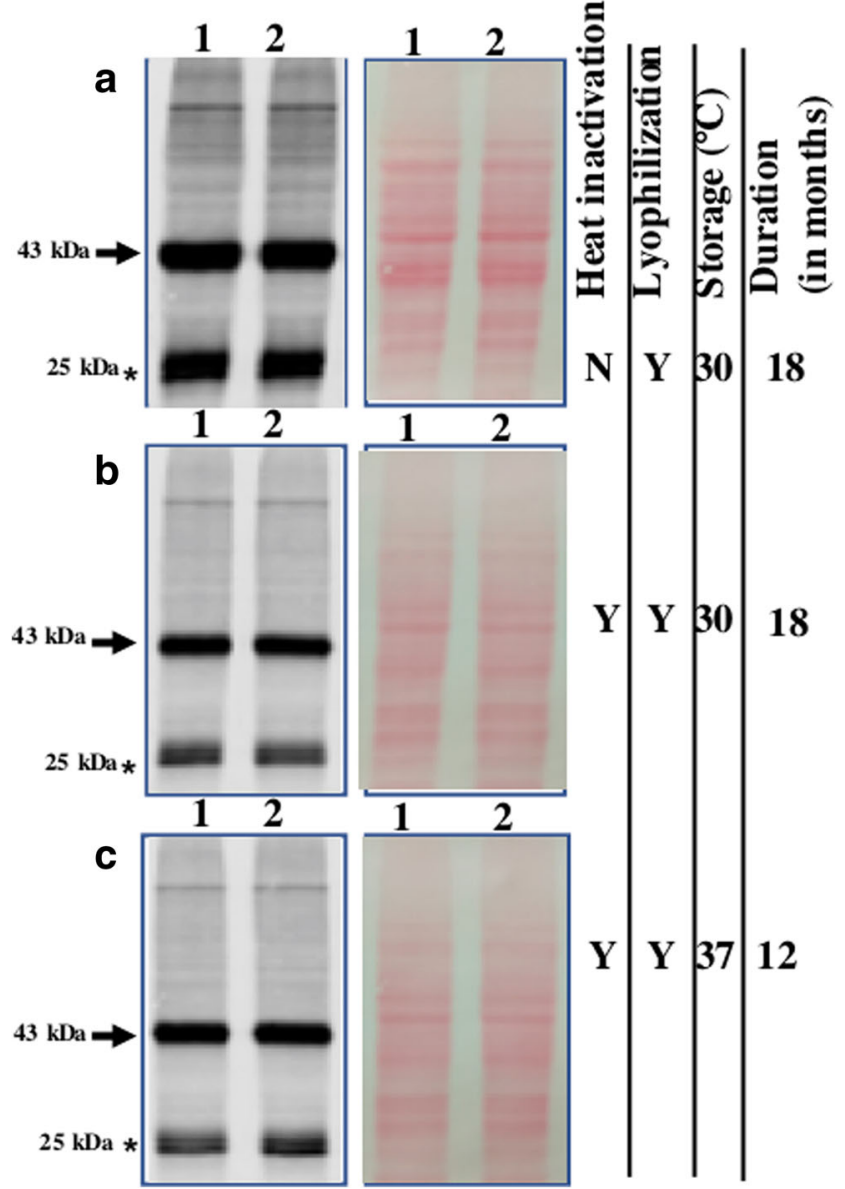

Fig. 4 Expressed protein remains stable in powdered yeast. (A) Stability of CSGA-GFP in freeze-dried yeast powder stored at $30^{\circ} \mathrm{C}$ after 1.5 year. (B) Stability of CSGA-GFP in heat-inactivated lyophilized yeast powder stored at $30{ }^{\circ} \mathrm{C}$ after 1.5 year. (C) Stability of heat-inactivated lyophilized yeast powder stored at $37{ }^{\circ} \mathrm{C}$ after 12 months. In each case, proper loading is shown, by Ponceau S-stained blot image (right side of each blot image). Note, the protein amount was normalized, based on yeast powder used for protein extraction. Bands of interest are pointed by arrows towards them, while free GFP is pointed by an Asterisk mark. Note in figure $\mathrm{Y}$ stand for yes and $\mathrm{N}$ for no for condition mentioned in the figure

inactivation (Fig. 4A) and in which cells were lyophilized after heat-inactivation (Fig. 4B). Before incubation in blocking buffer blots were stained with Ponceau $\mathrm{S}$ for showing the loading control (right side of each blot).

Encouraged from the stability of the protein in lyophilized powder stored at $30{ }^{\circ} \mathrm{C}$ for 1.5 years, we further checked whether expressed protein also remains stable in lyophilized yeast cells stored at $37^{\circ} \mathrm{C}$ for 1 year. Present western blot data showed that expressed protein remains stable in powdered yeast even when stored at $37{ }^{\circ} \mathrm{C}$ at least for twelve months (Fig. 4C). Loading control is shown on right side of blot image. Based on the present data, it can be said that expressed protein remains stable in lyophilized yeast cells when stored at a temperature ranging from 30 to $37^{\circ} \mathrm{C}$ for quite a long time.

We further calculate the cellular abundance of expressed protein antigen in per milligram of dry yeast powder. Quantitative estimation of antigen in dry yeast powder was performed by quantitative western blot. Present quantitative western blot showed that at the end of 18 months $2.125 \mu \mathrm{g}$ of expressed antigen was present per $\mathrm{mg}$ of lyophilized yeast powder stored at $30^{\circ} \mathrm{C}$ while $1.9 \mu \mathrm{g}$ of expressed antigen was present per $\mathrm{mg}$ of lyophilized yeast powder stored at $37^{\circ} \mathrm{C}$ for 12 months (data not shown). It was further calculated that $1 \mathrm{mg}$ lyophilized yeast powder corresponds to $\approx 2 \mathrm{OD}_{600 \mathrm{~nm}}$ of cells (data not shown). Note for our calculation we use intensity of only CSGA-GFP band without taking into consideration of free GFP (in vacuoles) bands at $25 \mathrm{kDa}$ region of blot. The amount of expressed antigen can be increased by selecting transformants with multiple integration which is quite common in K. phaffii (Vogl et al. 2018; Betancur et al. 2017). Strains used in present study had single copy integration of $E$. coli CSGA-GFP.

\section{Freeze and thaw do not affect protein stability in powdered yeast}

Most of the commonly used vaccines are stored at $2-8^{\circ} \mathrm{C}$, while some of them are also stored at -15 to $-50{ }^{\circ} \mathrm{C}$ (e.g., measles, mumps, and rubella or $\mathrm{MMR}_{\mathrm{I}}$ is stored at +8 to $-50{ }^{\circ} \mathrm{C}$, https:// www.merckvaccines.com/mmr/storage-handling/). However, for most vaccines exposure to sub-optimal temperature (i.e., more than $2-8{ }^{\circ} \mathrm{C}$ or below freezing temperature) even for a short duration is known to reduce vaccine potency dramatically (Brandau et al. 2003; Hill et al. 2016). An ideal vaccine should remain stable and retain potency even when stored under the non-refrigerated condition as well as under accidental freeze condition. For investigating the effect of freeze and thaw on the stability of the heterologous protein in lyophilized yeast cells, known amount of yeast powder was taken into separate tubes. Present western blot data showed that expressed protein in lyophilized yeast powder remain stable following one as well as two cycles of freeze and thaw at both $-20^{\circ} \mathrm{C}$ (Fig. 5A) and $-80{ }^{\circ} \mathrm{C}$ (Fig. 5B). Ponceau S-stained image of the membrane (as a loading control) is shown next to the blot. A known amount of yeast powder stored at $30^{\circ} \mathrm{C}$ separately was taken as a control. Based on the present data, it can be concluded that expressed protein remains stable under the non-refrigerated condition for a year as well as under freeze and thaw condition.

\section{The abundance of expressed protein after a year was similar to fresh cells}

In the previous section, we showed that the expressed CSGAGFP fusion protein was stable in lyophilized yeast powder when stored at $30{ }^{\circ} \mathrm{C}$ for 1.5 years and also survived two cycles of freeze and thaw. But whether the expressed protein deteriorated over time and if yes, then to what extent was missing. To answer this question, we compared the level of expressed protein in yeast powder stored for a year to the freshly lyophilized yeast cells. Before comparing the level of 
Fig. 5 Freeze and thaws do not affect the stability of the expressed protein. (A) Effect of freeze and thaw at $-20{ }^{\circ} \mathrm{C}$.

Control (lyophilized powder stored at $30^{\circ} \mathrm{C}$ ), well 1,2 (one cycle of freeze and thaw), well 3,4 (two-cycle of freeze and thaw).

(B) Effect of freeze and thaw at $80^{\circ} \mathrm{C}$. Same common control as above, well 1,2 (one cycle of freeze and thaw), well 3,4 (twocycle of freeze and thaw). Note, in all cases, the protein amount was normalized based on the weight of powder and, each sample was taken in duplex. Loading and proper transfer are shown through Ponceau S- stained of same blots. Also, a control sample is common in panel $\mathrm{A}$ and $\mathrm{B}$

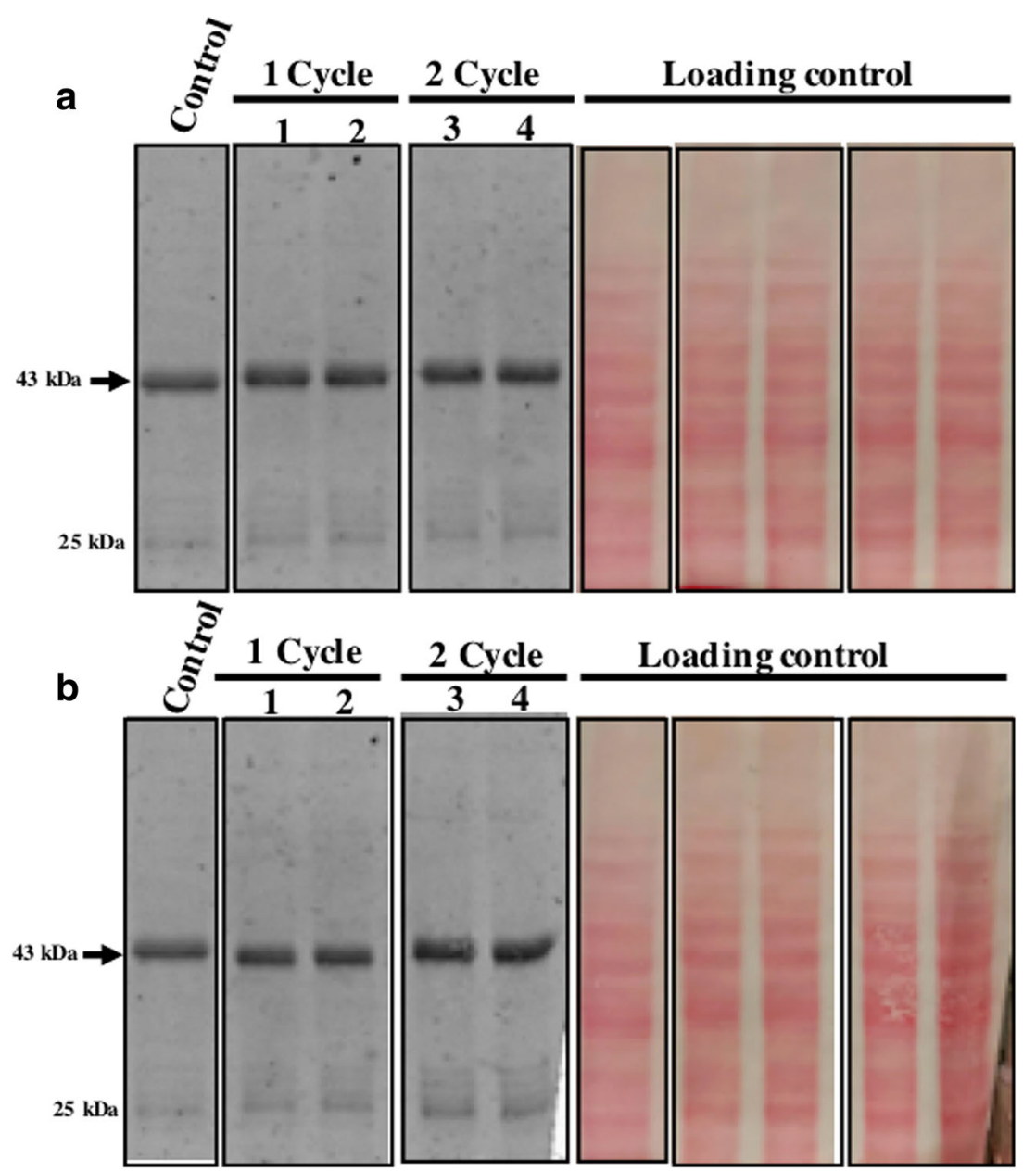

fusion proteins, we checked the overall protein content in the two samples (Fig. 6A). Although an equal amount of wholecell lysate was loaded for each sample we still saw a slightly low level of proteins in a sample from a year-old powder (well 6,7) compared to freshly lyophilized cells (well 4,5). Apart from this we also observed relatively more background in a year-old sample. Whether the observed difference in the level of proteins and background is due to the difference in protein extraction efficiencies or protein degradation is unclear. But we do find a problem in re-suspending the powder entirely even on vigorous vortex. We also loaded an equal amount of cell lysate from normal cycling cells as control (well 2,3).

After looking at the overall proteome of lyophilized cells stored for a year and freshly lyophilized cells, we proceed to compare the level of the expressed fusion protein in two samples. Present data (Fig. 6B) shows that level of the CSGAGFP fusion protein is almost similar in freshly lyophilized cells (Fig. 6B, well 4) to that of 1 -year-old powder (Fig. 6B, well 2,3). Note we used the same sample for western blot which were used in running SDS-PAGE shown in Fig. 6A. The slight difference which appears in two samples may be due to the issues mentioned above. Loading control is shown, by Ponceau-S-stained image of the same blot (Fig. 6C). To capture any possible difference in samples, blot images were captured at low intensity of exposure (data for high exposure is not shown).

\section{Discussions}

Storage, transportation, and distribution of vaccines are a twoway problem. On one hand, exposure of vaccine to temperatures more than the recommended temperatures (generally 2 $8{ }^{\circ} \mathrm{C}$ ) leads to vaccine degradation, denaturation and finally loss of vaccine potency or efficacy (Brandau et al. 2003; Hill et al. 2016). On the other hand, exposure of vaccines to below freezing conditions also affects vaccine potency (Lloyd et al. 2015; Kumru et al. 2014). Therefore, maintenance of optimum conditions from point of manufacturing till the final application is a must. Availability of thermostable vaccines will be an important step in global immunization step (Lee et al. 2017). The thermostable nature of future vaccines will not only make vaccine transport, storage and distribution more convenient and economical but will also help in saving a huge 


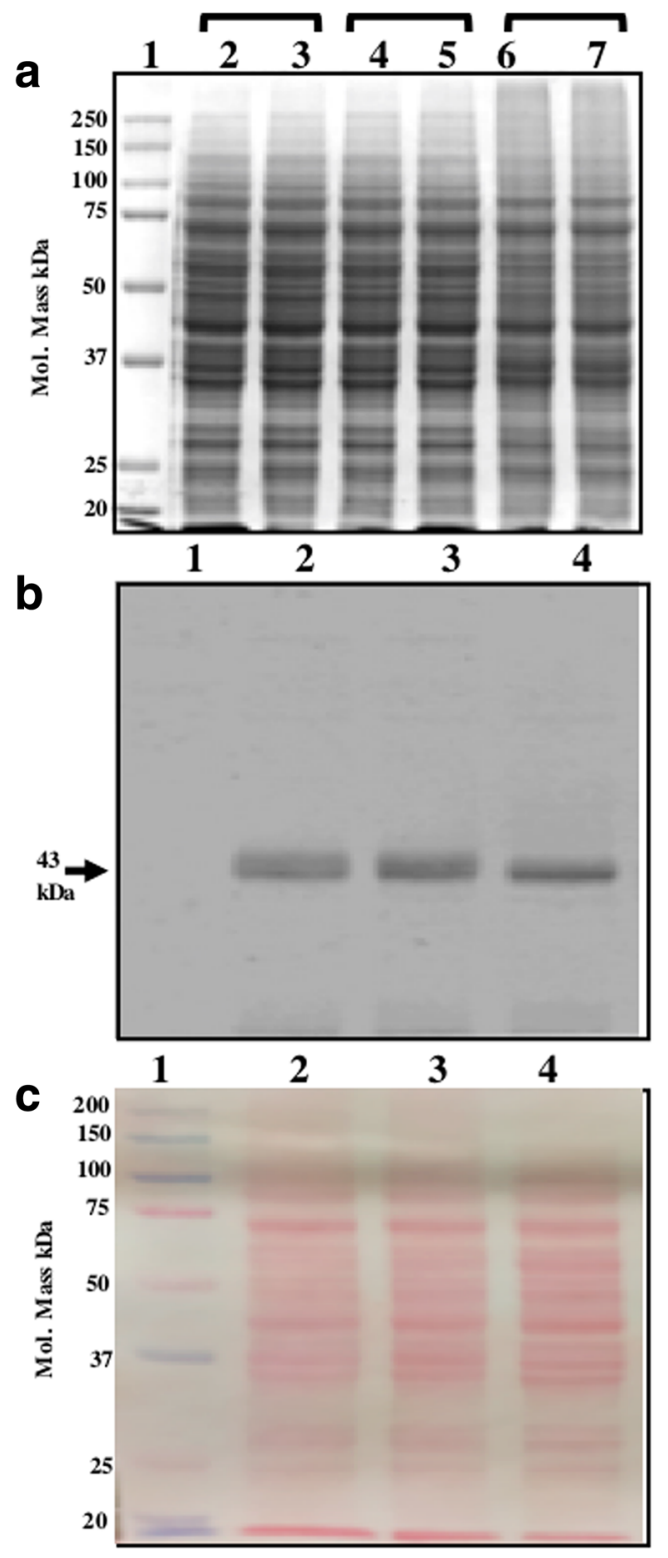

Fig. 6 The abundance of heterologous protein in a year old powdered and freshly lyophilized cells are similar. (A) The efficiency of protein extraction from different samples. Cycling cells without lyophilized (well 2,3), an equivalent number of cells after lyophilized powder (well 4,5), an equivalent amount of lyophilized powder stored at $30^{\circ} \mathrm{C}$ for 1 year (well 6,7 ), well 1 for protein marker. (B) The abundance of expressed protein is similar in freshly lyophilized cells and year-old lyophilized powder after 1 year at $30{ }^{\circ} \mathrm{C}$ (well 2,3), freshly prepared powder (well 4) and protein marker (well 1). The same blot was Ponceau S-stained before blocking in skimmed milk powder in TBST shown as a loading control (C)

number of life-saving vaccines. Although resource poor countries of Africa and Asia will be the one who gets maximum benefit from availability of thermostable vaccines, but uncertain weather conditions (example recent heavy snowfall in Texas, USA) (https://www.washingtonpost.com/weather/ 2021/02/16/winter-storm-live-updates/) and associated power outrage for a week suggests that thermostable vaccines are important for highly developed countries also. Data shown in present study showed that yeast-based platform can provide solution to vaccine degradation at high temperature as well as due to unwanted deep freezing.

Currently, the development of thermostable vaccinesare yet unmet with little success in which thermal stability was observed (only for a few months at best and that too in few cases) (Leung et al. 2019; Chu et al. 2016; Mistilis et al. 2017; Hassett et al. 2013; Hassett et al. 2015; Chen et al. 2010; Ohtake et al. 2010; Ohtake et al. 2011; Lovalenti et al. 2016). Thin-film coating was able to keep the adenovirus stable atambient temperature for 3 years (Bajrovic et al. 2020). But whether these approaches can also protect vaccines from unwanted freezing remains unknown. It will be interesting to see whether this approach can be applied to other vaccines. Whether the developed formulation applies to a wide range of vaccines also remain a matter of future research. Unlike conventional vaccine preparation which requires growth of bacterial culture or viral particles followed by formalin-based inactivation which itself is quite lengthy, growth and heat-inactivation of yeast are rapid and more economical. Clearly yeast-based vaccines can be a simple solution to all these issues and our present study is an important step in that direction of developing thermostable vaccine with increased shelf life which can remain stable even under undesirable freezing conditions.

The natural adjuvant nature of yeast cell walls (due to $\beta-1$, 3-d-glucans and yeast glycoproteins ) makes it possible to use lyophilized recombinant cells without the addition of an external adjuvant (Stubbs et al. 2001; Soto et al. 2010; Tesz et al. 2011; Tipper and Szomolanyi-Tsuda 2016). Unlike subunit vaccine, the yeast-based vaccines do not require protein purification. Yeast cells are efficiently taken up by antigenpresenting cells (Xiang et al. 2006). Handling of recombinant yeast is much easy and safer compared to infectious biological entities. Most importantly, the application of inactivated S. cerevisiae cells is found safe and well-tolerated in human subjects (Gaggar et al. 2014). Pre-clinical studies in mouse showed that injection of inactivated $K$. phaffii is well tolerated thus paving the way for more pre-clinical or clinical studies (Bolhassani et al. 2014).

Through this study, we showed the stability of heterologous protein for a 1.5 years $\left(\right.$ at $30^{\circ} \mathrm{C}$ ) and 1 year $\left(\right.$ at $37^{\circ} \mathrm{C}$ ) and we expect that expressed protein may remain stable even for much longer duration. Previous observation that antigenpresenting cells can process freeze-dried yeast cells and can mount an immune response further boost present study (Patterson et al. 2015) suggesting that whole recombinant lyophilized yeast powder can be a promising way for development of thermostable vaccines. Although application of lyophilization for freeze drying of yeast may be important but can be costly and may require more optimization for best results. But owing to continuous maintenance of cold chain 
and problem of unwanted freezing, finding right adjuvant and need for safety assessment for each chemical added in vaccine formulation is outward by the advantages of using lyophilized yeast for thermostable vaccines.

Overall, we have shown that a dry yeast powder is a simple yet effective way for long-term storage of vaccines (immunogen) under non-refrigerated condition. Data shown in this report showed that yeast-based approach for thermostable vaccine development prevents vaccine deterioration both at high temperature (above $2-8{ }^{\circ} \mathrm{C}$ ) as well as below freezing condition (below $0^{\circ} \mathrm{C}$ ) which is common in countries of Europe, North America, and parts of Asia. We believe that this cost-effective freeze-dried yeast powder approach may be one solution to the cold chain problem and can boost universal immunization programmes including on-going vaccination against Covid-19.

Acknowledgements We are thankful to the University of California San Francisco, San Francisco (UCSF), California-USA, for providing space and other necessary facilities towards completing this manuscript. We are also thankful to Prof. Geoff Lin-Cereghino from Pacific University, Stockton, California-USA, for providing SMD1 163 strain, Prof. Robert Stroud from UCSF for electroporation of yeast cells. We are also thankful to the staff at the University of California Berkeley Electron Microscope Laboratory for advice and assistance in electron microscopy, sample preparation, and data collection. We also extend our sincere thanks to Prof. Tejal A Desai for allowing access to lyophilizer. We are especially thankful to Prof. Jennifer C. Fung for allowing us to carry out this work in her lab.

\section{Code availability Not applicable}

Author contribution RK conceived, designed, performed the experiments, analyzed the data, and wrote the manuscript. BNK perform SEM microscopy.

Data availability All data generated or analyzed during this study are included in this published article.

\section{Declarations}

Ethics approval The authors declare that the present study does not involve any human subjects or animal handling by any author mentioned in this study.

Consent to participate Not applicable

Consent for publication Not applicable

Conflict of interest The authors declare no competing interests.

\section{References}

Alcock R, Cottingham MG, Rollier CS, Furze J, De Costa SD, Hanlon M, Spencer AJ, Honeycutt JD, Wyllie DH, Gilbert SC, Bregu M, Hill AV (2010) Long-term thermostabilization of live poxviral and adenoviral vaccine vectors at supraphysiological temperatures in carbohydrate glass. Sci Transl Med 2:19ra12

Bajrovic I, Schafer SC, Romanovicz DK, Croyle MA (2020) Novel technology for storage and distribution of live vaccines and other biological medicines at ambient temperature. Sci Adv 6:eaau4819

Barnhart MM, Chapman MR (2006) Curli biogenesis and function. Annu Rev Microbiol 60:131-147

Basanta A, Gómez-Sala B, Sánchez J, Diep DB, Herranz C, Hernández PE, Cintas LM (2010) Use of the yeast Pichia pastoris as an expression host for secretion of enterocin L50, a leaderless two-peptide (L50A and L50B) bacteriocin from Enterococcus faecium L50. Appl Environ Microbiol 76:3314-3324

Betancur MO, Reis VCB, Nicola AM, De Marco JL, de Moraes LMP, Torres FAG (2017) Multicopy plasmid integration in Komagataella phaffii mediated by a defective auxotrophic marker. Microb Cell Factories 16:99

Bolhassani A, Muller M, Roohvand F, Motevalli F, Agi E, Shokri M, Rad MM, Hosseinzadeh S (2014) Whole recombinant Pichia pastoris expressing HPV16 L1 antigen is superior in inducing protection against tumor growth as compared to killed transgenic Leishmania. Hum Vaccin Immunother 10:3499-3508

Brandau D, Jones L, Wiethoff CM, Rexroad J, Middaugh CR (2003) Thermal stability of vaccines. J Pharm Sci 92:218-231

Callaway E (2020) The race for coronavirus vaccines: a graphical guide. Nature 580:576-577

Chen D, Kristensen D (2009) Opportunities and challenges of developing thermostable vaccines. Expert Rev Vaccines 8:547-557

Chen D, Kapre S, Goel A, Suresh K, Beri S, Hickling J, Jensen J, Lal M, Preaud JM, Laforce M, Kristensen D (2010) Thermostable formulations of a hepatitis B vaccine and a meningitis A polysaccharide conjugate vaccine produced by a spray drying method. Vaccine 28 : 5093-5099

Chu LY, Ye L, Dong K, Compans RW, Yang C, Prausnitz MR (2016) Enhanced stability of inactivated influenza vaccine encapsulated in dissolving microneedle patches. Pharm Res 33:868-878

Crameri A, Whitehorn EA, Tate E, Stemmer WP (1996) Improved green fluorescent protein by molecular evolution using DNA shuffling. Nat Biotechnol 14:315-319

Cruz-Reséndiz A, Zepeda-Cervantes J, Sampieri A, Bastián-Eugenio C, Acero G, Sánchez-Betancourt JI, Gevorkian G, Vaca L (2020) A self-aggregating peptide: implications for the development of thermostable vaccine candidates. BMC Biotechnol 20:1

Das P (2004) Revolutionary vaccine technology breaks the cold chain. Lancet Infect Dis 4:719

Fenner F (1982) A successful eradication campaign. Global eradication of smallpox. Rev Infect Dis 4:916-930

Franzusoff A, Duke RC, King TH, Lu Y, Rodell TC (2005) Yeasts encoding tumour antigens in cancer immunotherapy. Expert Opin Biol Ther 5:565-575

Gaggar A, Coeshott C, Apelian D, Rodell T, Armstrong BR, Shen G, Subramanian GM, McHutchison JG (2014) Safety, tolerability and immunogenicity of GS-4774, a hepatitis B virus-specific therapeutic vaccine, in healthy subjects: a randomized study. Vaccine 32:49254931

Garmise RJ, Staats HF, Hickey AJ (2007) Novel dry powder preparations of whole inactivated influenza virus for nasal vaccination. AAPS Pharm Sci Tech 8:2-10

Gleeson MA, White CE, Meininger DP, Komives EA (1998) Generation of protease-deficient strains and their use in heterologous protein expression. Methods Mol Biol 103:81-94

Gould SJ, McCollum D, Spong AP, Heyman JA, Subramani S (1992) Development of the yeast Pichia pastoris as a model organism for a genetic and molecular analysis of peroxisome assembly. Yeast 8: 613-628

Haller AA, Lauer GM, King TH, Kemmler C, Fiolkoski V, Lu Y, Bellgrau D, Rodell TC, Apelian D, Franzusoff A, Duke RC 
(2007) Whole recombinant yeast-based immunotherapy induces potent $\mathrm{T}$ cell responses targeting HCV NS3 and Core proteins. Vaccine 25:1452-1463

Hassett KJK, Cousins MC, Rabia LA, Chadwick CM, O'Hara JM, Nandi P, Brey RN, Mantis NJ, Carpenter JF, Randolph TW (2013) Stabilization of a recombinant ricin toxin A subunit vaccine through lyophilization. Eur J Pharm Biopharm 85:279-286

Hassett KJ, Vance DJ, Jain NK, Sahni N, Rabia LA, Cousins MC, Joshi S, Volkin DB, Middaugh CR, Mantis NJ, Carpenter JF, Randolph TW (2015) Glassy-state stabilization of a dominant negative inhibitor anthrax vaccine containing aluminum hydroxide and glycopyranoside lipid A adjuvants. J Pharm Sci 104:627-639

Hill A, Kilgore C, McGlynn M, Jones CH (2016) Improving global vaccine accessibility. Curr Opin Biotechnol 42:67-73

Klionsky DJ, Cuervo AM, Seglen PO (2007) Methods for monitoring autophagy from yeast to human. Autophagy 3:181-206

Kumar R (2018) Investigating the long-term stability of protein immunogen(s) for whole recombinant yeast-based vaccines. FEMS Yeast Res 18:1-13

Kumar R (2019) Simplified protocol for faster transformation of (a large number of) Pichia pastoris strains. Yeast 36:399-410

Kumar R, Kumar P (2019) Yeast-based vaccines: new perspective in vaccine development and application. FEMS Yeast Res 19:1-22

Kumar R, Dhali S, Srikanth R, Ghosh SK, Srivastava S (2014) Comparative proteomics of mitosis and meiosis in Saccharomyces cerevisiae. J Proteomics 109:1-15

Kumar R, Rahman MA, Nazarko TY (2020) Nitrogen starvation and stationary phase lipophagy have distinct molecular mechanisms. Int J Mol Sci 21:1-13

Kumru OS, Joshi SB, Smith DE, Middaugh CR, Prusik T, Volkin DB (2014) Vaccine instability in the cold chain: mechanisms, analysis and formulation strategies. Biologicals 42:237-359

Kurtzman CP (2009) Biotechnological strains of Komagataella (Pichia) pastoris are Komagataella phaffii as determined from multigene sequence analysis. J Ind Microbiol Biotechnol 36:1435-1438

Lee BY, Wedlock PT, Haidari LA, Elder K, Potet J, Manring R, Connor DL, Spiker ML, Bonner K, Rangarajan A, Hunyh D, Brown ST (2017) Economic impact of thermostable vaccines. Vaccine 35: 3135-3142

Leung V, Mapletoft J, Zhang A, Lee A, Vahedi F, Chew M, Szewczyk A, Jahanshahi-Anbuhi S, Ang J, Cowbrough B, Miller MS, Ashkar A, Filipe CDM (2019) Thermal stabilization of viral vaccines in lowcost sugar films. Sci Rep 9:7631

Lloyd J, Lydon P, Ouhichi R, Zaffran M (2015) Reducing the loss of vaccines from accidental freezing in the cold chain: the experience of continuous temperature monitoring in Tunisia. Vaccine 33:902907

Lovalenti PM, Anderl J, Yee L, Nguyen V, Ghavami B, Ohtake S, Saxena A, Voss T, Truong-Le V (2016) Stabilization of live attenuated influenza vaccines by freeze drying, spray drying, and foam drying. Pharm Res 33:1144-1160

Lu Y, Bellgrau D, Dwyer-Nield LD, Malkinson AM, Duke RC, Rodell TC, Franzusoff A (2004) Mutation-selective tumor remission with Ras-targeted, whole yeast-based immunotherapy. Cancer Res 64: 5084-5088

Maa YF, Ameri M, Shu C, Payne LG, Chen D (2004) Influenza vaccine powder formulation development: spray-freeze-drying and stability evaluation. J Pharm Sci 93:1912-1923

Milistien JB, Stanley ML, Peter FW (1997) Development of a more thermostable poliovirus vaccine. J Infect Dis 175(Suppl 1):S247S253

Mistilis MJ, Joyce JC, Esser ES, Skountzou I, Compans RW, Bommarius AS, Prausnitz MR (2017) Long-term stability of influenza vaccine in a dissolving microneedle patch. Drug Deliv Transl Res 7:195205

Nguyen P, Botyanszki Z, Tay PK, Joshi NS (2014) Programmable biofilm-based materials from engineered curli nanofibres. Nat Commun 5:4945

Norrby E, Uhnoo I, Brytting M, Zakikhany K, Lepp T, Olin P (2017) Polio close to eradication. Lakartidningen. 114:EPDT.

Ohtake S, Martin RA, Yee L, Chen D, Kristensen DD, LechugaBallesteros D, Truong-Le V (2010) Heat-stable measles vaccine produced by spray drying. Vaccine 28:1275-1284

Ohtake S, Martin R, Saxena A, Pham B, Chiueh G, Osorio M, Kopecko D, Xu D, Lechuga-Ballesteros D, Truong-Le V (2011) Room temperature stabilization of oral, live attenuated Salmonella enterica serovar Typhi-vectored vaccines. Vaccine 29:2761-2771

Patterson R, Eley T, Browne C, Martineau HM, Werling D (2015) Oral application of freeze-dried yeast particles expressing the PCV2b Cap protein on their surface induce protection to subsequent PCV2b challenge in vivo. Vaccine 33:6199-6205

Pelliccia M, Andreozzi P, Paulose J, D'Alicarnasso M, Cagno V, Donalisio M, Civra A, Broeckel RM, Haese N, Jacob Silva P, Carney RP, Marjomäki V, Streblow DN, Lembo D, Stellacci F, Vitelli V, Krol S (2016) Additives for vaccine storage to improve thermal stability of adenoviruses from hours to months. Nat Commun 7:13520

Ramchuran SO, Mateus B, Holst O, Karlsson EN (2005) The methylotrophic yeast Pichia pastoris as a host for the expression and production of thermostable xylanase from the bacterium Rhodothermus marinus. FEMS Yeast Res 5:839-850

Sears IB, O'Connor J, Rossanese OW, Glick BS (1998) A versatile set of vectors for constitutive and regulated gene expression in Pichia pastoris. Yeast 14:783-790

Soto E, Kim YS, Lee J, Kornfeld H, Ostroff G (2010) Glucan Particle Encapsulated Rifampicin for Targeted Delivery to Macrophages. Polymers 2:681-689

Stubbs AC, Martin KS, Coeshott C, Skaates SV, Kuritzkes DR, Bellgrau D, Franzusoff A, Duke RC, Wilson CC (2001) Whole recombinant yeast vaccine activates dendritic cells and elicits protective cellmediated immunity. Nat Med 7:625-629

Takeshige K, Baba M, Tsuboi S, Noda T, Ohsumi Y (1992) Autophagy in yeast demonstrated with proteinase-deficient mutants and conditions for its induction. J Cell Biol 119:301-311

Tesz GJ, Aouadi M, Prot M, Nicoloro SM, Boutet E, Amano SU, Goller A, Wang M, Guo CA, Salomon WE, Virbasius JV, Baum RA, O'Connor MJ Jr, Soto E, Ostroff GR, Czech MP (2011) Glucan particles for selective delivery of siRNA to phagocytic cells in mice. Biochem J 436:351-362

Tipper DJ, Szomolanyi-Tsuda E (2016) Scaffolded Antigens in Yeast Cell Particle Vaccines Provide Protection against Systemic Polyoma Virus Infection. J Immunol Res 2016:2743292

Towbin H, Staehelin T, Gordon J (1979) Electrophoretic transfer of proteins from polyacrylamide gels to nitrocellulose sheets: procedure and some applications. PNAS USA 76:4350-4354

Versteeg L, Almutairi MM, Hotez PJ, Pollet J (2019) Enlisting the mRNA vaccine platform to combat parasitic infections. Vaccines (Basel) 7:122

Vogl T, Gebbie L, Palfreyman RW, Speight R (2018) Effect of Plasmid Design and Type of Integration Event on Recombinant Protein Expression in Pichia pastoris. Appl Environ Microbiol 84: e02712-e02717

Wang SH, Kirwan SM, Abraham SN, Staats HF, Hickey AJ (2012) Stable dry powder formulation for nasal delivery of anthrax vaccine. J Pharm Sci 101:31-47 
Wang G, Cao RY, Chen R, Mo L, Han JF, Wang X, Xu X, Jiang T, Deng YQ, Lyu K, Zhu SY, Qin ED, Tang R, Qin CF (2013) Rational design of thermostable vaccines by engineered peptide-induced virus self-biomineralization under physiological conditions. PNAS USA 110:7619-7624
Xiang SD, Scholzen A, Minigo G, David C, Apostolopoulos V, Mottram PL, Plebanski M (2006) Pathogen recognition and development of particulate vaccines: does size matter? Methods 40:1-9

Publisher's note Springer Nature remains neutral with regard to jurisdictional claims in published maps and institutional affiliations. 